\title{
Associations of Mitochondrial Deoxyribonucleic Acid Polymorphisms With Behçet's Disease in the Korean Population
}

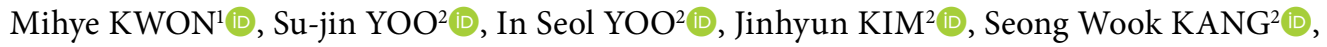 \\ In $\mathrm{Ah} \mathrm{CHOI}^{3} \mathbb{D}$, Mi-kyoung $\mathrm{LIM}^{4} \mathbb{B}$, Chung-il JOUNG ${ }^{1}$ \\ ${ }^{1}$ Department of Internal Medicine, Konyang University School of Medicine, Myunggok Medical Research Institute, Daejeon, South Korea \\ ${ }^{2}$ Department of Internal Medicine, Chungnam National University School of Medicine, Daejeon, South Korea \\ ${ }^{3}$ Department of Internal Medicine, Chungbuk National Univeristy School of Medicine, Cheonan, South Korea \\ ${ }^{4}$ Department of Internal Medicine, Eulji University School of Medicine, Daejeon, South Korea
}

\begin{abstract}
Objectives: This study aims to examine the possible associations of mitochondrial single nucleotide polymorphisms (SNPs) and Behçet's disease (BD) in a larger patient group.

Patients and methods: Whole blood or buffy coat was collected from 98 BD patients (31 males, 67 females; mean age $48 \pm 2.8$ years; range 20 to 60 years) from four university hospitals located in the Chung-Cheong district of the Republic of Korea, and 196 age- and sex-matched healthy controls (HCs) (62 males, 134 females; mean age $46.91 \pm 12.90$ years; range 20 to 68 years) from Konyang University Hospital. Twenty targeted mitochondrial deoxyribonucleic acids (DNAs) were genotyped and compared using the revised Cambridge Reference Sequence. Chi square and Fisher's exact tests were used to analyze association of mitochondrial DNA SNPs with BD susceptibility and its clinical characteristics.

Results: There were no differences for m.248A $>\mathrm{G}, \mathrm{m} .304 \mathrm{C}>\mathrm{A}, \mathrm{m} .709 \mathrm{G}>\mathrm{A}, \mathrm{m} .3010 \mathrm{G}>\mathrm{A}, \mathrm{m} .3970 \mathrm{C}>\mathrm{T}, \mathrm{m} .4883 \mathrm{C}>\mathrm{T}, \mathrm{m} .5178 \mathrm{C}>\mathrm{A}, \mathrm{m} .6392 \mathrm{~T}>\mathrm{C}$, m.6962G >A, m.10310G >A, m.10609T>C, m.12406G >A, m.12882C>T, m.13928G>C, m.14668C $>T$, m.16129G >A, and m16304T> between patient and HC groups. However, $\mathrm{m} .16182 \mathrm{~A}>\mathrm{C}$ and $\mathrm{m} .16183 \mathrm{~A}>\mathrm{C}$ were more frequently observed in the patient group than the $\mathrm{HC}$ group (22 [22.4\%] vs. 24 [12.2\%], $\mathrm{p}=0.061$ and 32 [32.7\%] vs. 42 [21.4\%], $\mathrm{p}=0.092$ ) but without statistical significance. $\mathrm{m} .4883 \mathrm{C}>\mathrm{T}$ and $\mathrm{m} .5178 \mathrm{C}>\mathrm{A}$ were associated with posterior location of oral ulcers ( $p=0.025$ for each) and $m .16183 A>C$ was associated with deep oral ulcers $(p=0.001)$, while $m .16189 T>C$ was associated with deep oral ulcers and thrombosis $(p=0.042,0.048$, respectively).

Conclusion: $\mathrm{m} .16182 \mathrm{~A}>\mathrm{C}$ and $\mathrm{m} .16183 \mathrm{~A}>\mathrm{C}$ may be associated with BD in the Korean population.

Keywords: Behçet's disease, etiology, mitochondrial deoxyribonucleic acid, single nucleotide polymorphism.
\end{abstract}

Behçet's disease (BD) is a rheumatic disorder characterized by recurrent oral ulcers, genital ulcers, uveitis and erythema nodosum-like skin lesions. It has several features of both autoimmune and autoinflammatory diseases. ${ }^{1}$ The predominant pathology of $\mathrm{BD}$ is vasculitis in vessels of various sizes and types. However, its cause requires further study. It is multifactorial and multigenetic, and several nuclear genetic changes have been suggested as possible pathogenic factors. Mitochondrial genetic alterations have scarcely been considered.

Mitochondrial diseases are emerging as novel and expanding disease entities; they include several inborn neuromuscular diseases, and their associations with other diseases are being investigated. Mitochondrial abnormalities are thought to contribute to cancers, diabetes mellitus,

Received: July 18, 2018 Accepted: September 28, 2018 Published online: January 28, 2019

Correspondence: Chung-il Joung, MD. Department of Internal Medicine, Konyang University School of Medicine, Myunggok Medical Research Institute, 35365 Daejeon, South Korea. Tel: 821030763029 e-mail: cij1221@kyuh.ac.kr

\section{Citation:}

Kwon M, Yoo SJ, Yoo IS, Kim J, Kang SW, Choi IA, et al. Associations of Mitochondrial Deoxyribonucleic Acid Polymorphisms With Behçet's Disease in the Korean Population. Arch Rheumatol 2019;34(2):211-219. 
and some autoimmune diseases. Although many researches have tried to elucidate pathogenesis and disease mechanisms of the disease, $\mathrm{BD}$ is still uncharted territory and mitochondrial genetic aberrations could be one of the hypotheses for a multifactorial disease like BD. A previous report has linked a mitochondrial single nucleotide polymorphism (SNP), m.709G $>\mathrm{A}$, to $\mathrm{BD}$ in the Iranian population. ${ }^{2}$ Our group sequenced nearly the entire mitochondrial deoxyribonucleic acid (DNA) sequence in 20 Korean BD patients and 10 sex-, and age-matched healthy controls (HCs) and found that the minor allele frequencies for $\mathrm{m} .248 \mathrm{~A}>\mathrm{G}, \mathrm{m} .709 \mathrm{G}>\mathrm{A}, \mathrm{m} .3970 \mathrm{C}>\mathrm{T}$, m.6392T $>C, \quad m .6962 G>A, \quad m .10310 G>A$, m.10609T $>C, \quad m .12406 G>A, \quad m .12882 C>T$, m.13928G $>$ C, m.16129G $>A$, and m16304T $>C$ were more frequent in $\mathrm{BD}$ patients though the differences were not statistically significant. ${ }^{3}$ Therefore, in this study, we aimed to examine the possible associations of mitochondrial SNPs and $\mathrm{BD}$ in a larger patient group.

\section{PATIENTS AND METHODS}

Ninety-eight BD patients (31 males, 67 females; mean age $48 \pm 2.8$ years; range 20 to 60 years) who met the 1999 Diagnostic Criteria of the International Study Group for Behçet's disease were enrolled from outpatient rheumatology clinics of Konyang University Hospital, Chungnam National University Hospital, Chungbuk National University Hospital, and Eulji University Hospital. located in Chung-Cheong district of the Republic of Korea between June 2016 and July 2017.4 A total of 196 age- and sex-matched HCs (62 males, 134 females; mean age 46.91 12.90 years; range 20 to 68 years) were enrolled from Konyang University Hospital. Patients with other autoimmune or autoinflammatory diseases were excluded. All patients' peripheral blood was drawn. The case records consisted of patients' current age, sex, time since diagnosis, symptom duration, family history of BD, clinical manifestations of oral and genital ulcers, erythema nodosumlike skin lesions, pseudofolliculitis, uveitis, optic neuritis, thrombosis, arthralgia and/or arthritis, gastrointestinal involvement and laboratory results including human leukocyte antigen B (HLA-B)*51 positivity. Medication status was also collected. The study protocol was approved by the Konyang

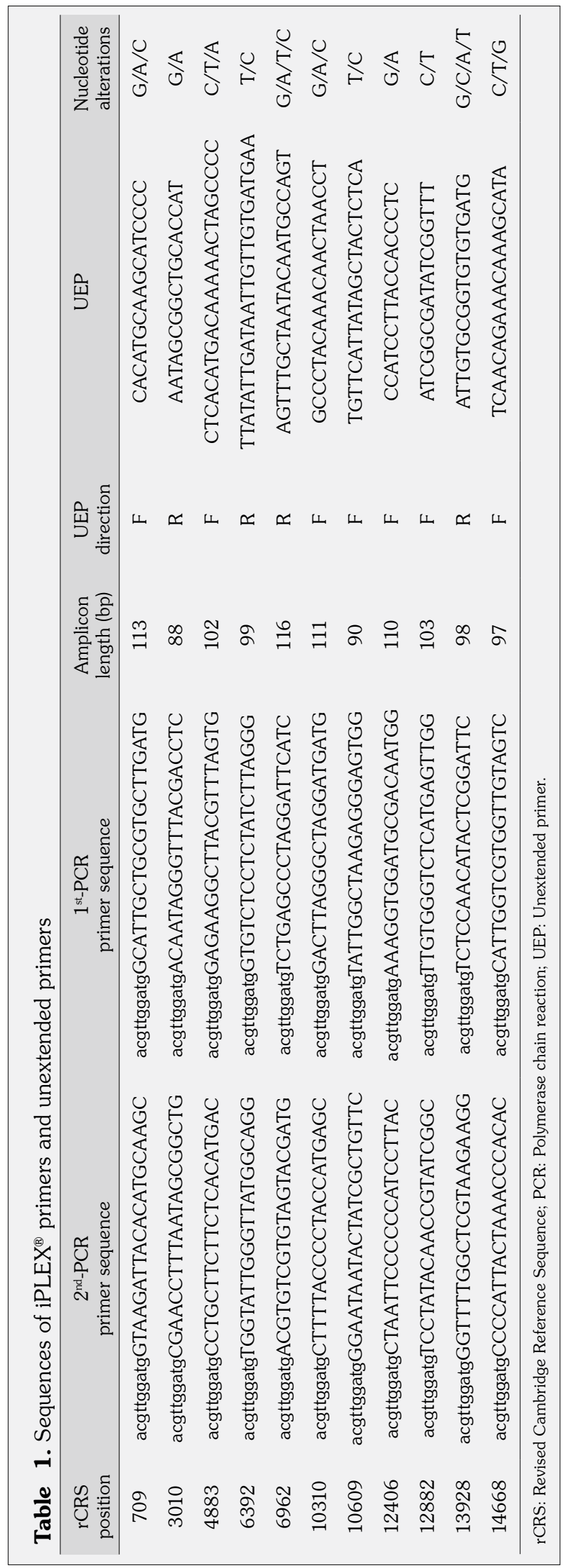


University Hospital Ethics Committee (Institutional Review Board approval no. KYUH 2015-10-024). A written informed consent was obtained from each participant. The study was conducted in accordance with the principles of the Declaration of Helsinki.

Genomic DNA was extracted from peripheral blood or buffy coats with the Qiagen GeneAll ExgeneTM Blood SV Kit ${ }^{\circledR}$ (GeneAll Biotechnology, Seoul, Korea), and DNA concentration was determined with a NanoDrop ND-1000 spectrophotometer (Thermo Fisher Scientific, Wilmington, DE, USA). Each sample was diluted to $10 \mathrm{ng} / \mu \mathrm{L}$.

Eleven mitochondrial DNA nucleotides (m.709, m.3010, m.4883, m.6392, m.6962, m.10310, m.10609, m.12406, m.12882, m.13928, and m.14668) were genotyped using the MassARRAY system (Agena BioScience Inc., San Diego, CA, USA) with the Assay Design Suite tool and iPLEX $^{\circledR}$ assay. All the primers used are listed in Table 1. Polymerase chain reactions (PCRs) were performed in a total volume of $5 \mu \mathrm{L}$ containing $10 \mathrm{ng}$ genomic DNA, $100 \mathrm{nM}$ of each amplification primer, $500 \mathrm{uM}$ deoxynucleotide triphosphate (dNTP) mix, $1.625 \mathrm{mM}$ magnesium chloride, and 0.5 units HotStar Taq DNA Polymerase (Qiagen, Valencia, CA, USA). The mixture was subjected to the following PCR conditions: a single denaturation cycle at $94^{\circ} \mathrm{C}$ for 15 minutes, followed by 45 cycles at $94^{\circ} \mathrm{C}$ for 20 seconds, $56^{\circ} \mathrm{C}$ for 30 seconds, $72^{\circ} \mathrm{C}$ for 60 seconds, and a final extension at $72^{\circ} \mathrm{C}$ for three minutes. Unincorporated nucleotides in the PCR product were deactivated using shrimp alkaline phosphatase. Allele discrimination reactions were conducted by adding the allele-specific extension primers, DNA polymerase and a cocktail of dNTPs and dideoxynucleotide triphosphates to each well. MassExtend clean resin (Agena BioScience Inc., San Diego, CA, USA) was added to the mixtures to remove extraneous salts that could interfere with matrix-assisted laser desorption ionization time-of-flight (MALDI-TOF) analysis. The desalted extension products were spotted onto silicon SpectroChip (Agena BioScience Inc., San Diego, CA, USA). Genotypes were determined by spotting an aliquot of each sample onto a 384 SpectroChip, which was subsequently read by the MALDI-TOF mass spectrometer.

m.3970 was genotyped using TaqManbased genotyping on an Applied Biosystems 7500 real-time PCR system (Applied Biosystems, Foster City, CA, USA). The primers used were as follows: forward, 5'- CCCTTCGACCTTGCCGAA-3' and reverse, 5'- GCGTCATATGTTGTTCCTAGGAAGA-3', wild-type allele probe, 5'- CCTTCGCCCTCTTCT-3', and mutant-type allele probe 5'- CCTTCGCCTTCTTCT- $5{ }^{\prime}{ }^{5}$ The $10 \mu \mathrm{L}$ PCR reaction mix comprised of $10 \mathrm{ng}$ genomic DNA and $5.0 \mu \mathrm{L}$ of $2 \times$ TaqMan Universal PCR master mix without uracil $\mathrm{N}$-glycosylase and $0.25 \mu \mathrm{L}$ of $40 \times$ SNP genotyping assay (Probes and Primers). Genotyping was performed according to the manufacturer's instructions.

m.5178 and the other seven mitochondrial DNA control region nucleotides, m.248, m.304, m.16129, m.16182, m.16183, m.16189, and m.16304 were Sanger sequenced. The PCR/Sanger Sequencing Primer pairs for m.5178 mitochondrially encoded NADH dehydrogenase 2 (MT-ND2) and the mitochondrial DNA control region are listed in Table 2 . PCR was performed in

Table 2. Polymerase chain reaction/Sanger sequencing primers used for m.5178 and mitochondrial deoxyribonucleic acid control region

\begin{tabular}{lrc}
\hline Primer & \multicolumn{1}{c}{ Sequence(5'-3') } & Usage \\
\hline m.5178F & ATCTCTCCCTCACTAAACGTAAGCCTT & PCR and Sequencing \\
m.5178R & TTAGTATAAAAGGGGAGATAGGTAGGAGTAGC & PCR and Sequencing \\
F15975 & CTC CAC CAT TAG CAC CCA AA & PCR and Sequencing \\
R635 & GAT GTG AGC CCG TCT AAA CA & PCR and Sequencing \\
F155 & TAT TTA TCG CAC CTA CGT TC & Sequencing \\
R16410m & GAG GAT GGT GGT CAA GGG A & Sequencing \\
\hline PCR: Polymerase chain reaction. & \\
\hline
\end{tabular}




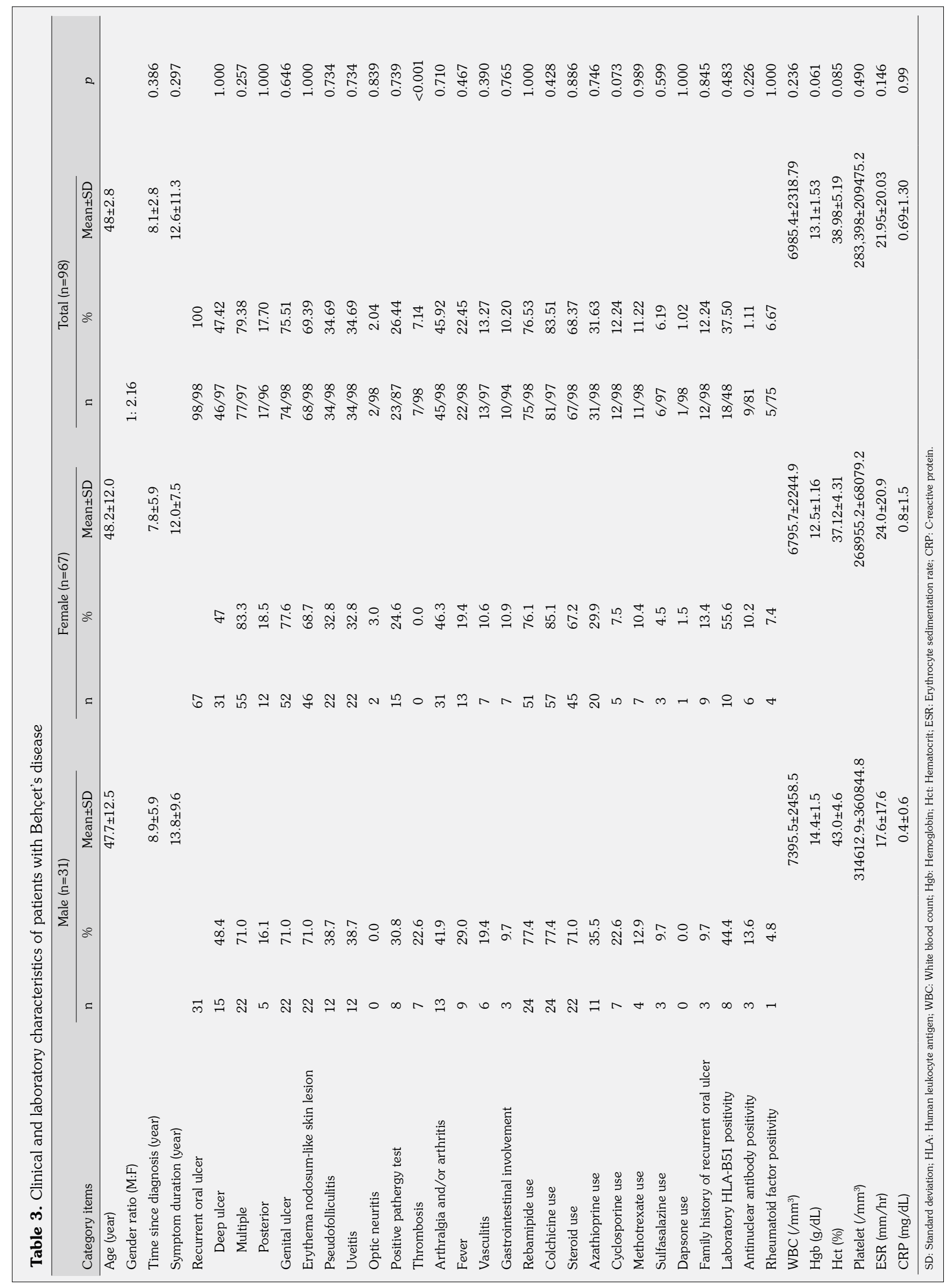


Table 4. Associations between mitochondrial deoxyribonucleic acid alterations and Behçet's disease

\begin{tabular}{|c|c|c|c|c|c|c|c|c|c|c|}
\hline \multirow[b]{2}{*}{$\begin{array}{l}\text { rCRS } \\
\text { position }\end{array}$} & \multirow[b]{2}{*}{$\begin{array}{l}\text { Map } \\
\text { locus }\end{array}$} & \multirow[b]{2}{*}{$\begin{array}{c}\text { Gene position } \\
\text { (np) }\end{array}$} & \multirow[b]{2}{*}{ Description } & \multirow[b]{2}{*}{$\begin{array}{l}\text { Nucleotide } \\
\text { alteration }\end{array}$} & \multicolumn{2}{|c|}{$\mathrm{BD}(\mathrm{n}=98)$} & \multicolumn{2}{|c|}{$\mathrm{HC}(\mathrm{n}=196)$} & \multirow[b]{2}{*}{$p$} & \multirow[b]{2}{*}{ OR* $(95 \% \mathrm{CI})$} \\
\hline & & & & & $\mathrm{n}$ & $\%$ & $\mathrm{n}$ & $\%$ & & \\
\hline 248 & MT-HV2 & $57-372$ & $\begin{array}{l}\text { Hypervariable } \\
\text { segment } 2\end{array}$ & A del & 12 & 12.2 & 23 & 11.7 & 1.000 & $1.050(0.499-2.209)$ \\
\hline 304 & MT-HV2 & $57-372$ & $\begin{array}{l}\text { Hypervariable } \\
\text { segment } 2\end{array}$ & $\mathrm{C}>\mathrm{A}$ & 0 & 0 & 0 & 0 & NA & NA \\
\hline 709 & MT-RNR1 & $648-1601$ & $\begin{array}{l}12 \mathrm{~S} \text { ribosomal } \\
\text { RNA }\end{array}$ & $\mathrm{G}>\mathrm{A}$ & 24 & 24.5 & 35 & 17.9 & 0.236 & $1.492(0.929-2.686)$ \\
\hline 3010 & MT-RNR2 & $1671-3229$ & $\begin{array}{l}16 S \text { ribosomal } \\
\text { RNA }\end{array}$ & $\mathrm{G}>\mathrm{A}$ & 19 & 19.4 & 50 & 25.5 & 0.307 & $0.702(0.387-1.273)$ \\
\hline 3970 & MT-ND1 & $3307-4262$ & $\begin{array}{c}\text { NADH } \\
\text { Dehydrogenase } \\
\text { subunit } 1\end{array}$ & $\mathrm{~T}>\mathrm{C}$ & 14 & 14.3 & 19 & 9.7 & 0.327 & $1.553(0.743-3.246)$ \\
\hline 4883 & MT-ND2 & $4470-5511$ & $\begin{array}{c}\text { NADH } \\
\text { Dehydrogenase } \\
\text { subunit } 2\end{array}$ & $\mathrm{C}>\mathrm{T}$ & 25 & 25.5 & 59 & 30.1 & 0.494 & $0.795(0.460-1.374)$ \\
\hline 5178 & MT-ND2 & $4470-5511$ & $\begin{array}{c}\text { NADH } \\
\text { Dehydrogenase } \\
\text { subunit } 2\end{array}$ & $\mathrm{C}>\mathrm{A}$ & 25 & 25.5 & 59 & 30.1 & 0.494 & $0.795(0.460-1.374)$ \\
\hline 6392 & MT-COI & $5904-7445$ & $\begin{array}{l}\text { Cytochrome c } \\
\text { oxidase subunit I }\end{array}$ & $\mathrm{T}>\mathrm{C}$ & 14 & 14.3 & 19 & 9.7 & 0.327 & $1.553(0.743-3.246)$ \\
\hline 6962 & MT-COI & $5904-7445$ & $\begin{array}{l}\text { Cytochrome c } \\
\text { oxidase subunit I }\end{array}$ & $\mathrm{G}>\mathrm{A}$ & 12 & 12.2 & 18 & 9.2 & 0.540 & $1.380(0.636-2.993)$ \\
\hline 10310 & MT-ND3 & $10059-10404$ & $\begin{array}{c}\text { NADH } \\
\text { Dehydrogenase } \\
\text { subunit } 3\end{array}$ & $\mathrm{G}>\mathrm{A}$ & 16 & 16.3 & 24 & 12.2 & 0.434 & $1.398(0.705-2.774)$ \\
\hline 10609 & MT-ND4L & $10470-10766$ & $\begin{array}{c}\text { NADH } \\
\text { Dehydrogenase } \\
\text { subunit } 4 \mathrm{~L}\end{array}$ & $\mathrm{~T}>\mathrm{C}$ & 12 & 12.2 & 16 & 8.2 & 0.361 & $1.570(0.711-3.463)$ \\
\hline 12406 & MT-ND5 & $12337-14148$ & $\begin{array}{c}\text { NADH } \\
\text { Dehydrogenase } \\
\text { subunit } 5\end{array}$ & $\mathrm{G}>\mathrm{A}$ & 12 & 12.2 & 17 & 8.7 & 0.447 & $1.469(0.672-3.213)$ \\
\hline 12882 & MT-ND5 & $12337-14148$ & $\begin{array}{c}\text { NADH } \\
\text { Dehydrogenase } \\
\text { subunit } 5\end{array}$ & $\mathrm{C}>\mathrm{T}$ & 12 & 12.2 & 16 & 8.2 & 0.361 & $1.570(0.711-3.463)$ \\
\hline 13928 & MT-ND5 & 12337-14148 & $\begin{array}{c}\text { NADH } \\
\text { Dehydrogenase } \\
\text { subunit } 5\end{array}$ & $\mathrm{G}>\mathrm{C}$ & 14 & 14.3 & 19 & 9.7 & 0.327 & $1.553(0.743-3.246)$ \\
\hline 14668 & MT-ND6 & $14149-14673$ & $\begin{array}{c}\text { NADH } \\
\text { Dehydrogenase } \\
\text { subunit } 6\end{array}$ & $\mathrm{C}>\mathrm{T}$ & 19 & 19.4 & 49 & 25.0 & 0.353 & $0.722(0.398-1.310)$ \\
\hline 16129 & MT-HV1 & $16024-16383$ & $\begin{array}{l}\text { Hypervariable } \\
\text { segment } 1\end{array}$ & $\mathrm{G}>\mathrm{A}$ & 23 & 23.5 & 42 & 21.4 & 0.804 & $1.124(0.631-2.005)$ \\
\hline 16182 & MT-HV1 & $16024-16383$ & $\begin{array}{c}\text { Hypervariable } \\
\text { segment } 1\end{array}$ & $A>C$ & 22 & 22.4 & 24 & 12.2 & 0.061 & 2.062 (1.089-3.906) \\
\hline 16183 & MT-HV1 & $16024-16383$ & $\begin{array}{l}\text { Hypervariable } \\
\text { segment } 1\end{array}$ & $A>C$ & 32 & 32.7 & 42 & 21.4 & 0.092 & $1.766(1.026-3.040)$ \\
\hline 16189 & MT-HV1 & $16024-16383$ & $\begin{array}{l}\text { Hypervariable } \\
\text { segment } 1\end{array}$ & $\mathrm{~T}>\mathrm{C}$ & 42 & 42.9 & 64 & 32.7 & 0.112 & $1.547(0.939-2.548)$ \\
\hline 16304 & MT-HV1 & $16024-16383$ & $\begin{array}{l}\text { Hypervariable } \\
\text { segment } 1\end{array}$ & $\mathrm{~T}>\mathrm{C}$ & 15 & 15.3 & 18 & 9.2 & 0.170 & $1.787(0.859-3.720)$ \\
\hline
\end{tabular}

BD: Behçet's disease; HC: Healthy control; rCRS: Revised Cambridge Reference Sequence; OR: Odds ratio; CI: Confidence interval; NA: Non-applicable; RNA: Ribonucleic acid; NADH: Nicotinamide adenine dinucleotide, reduced form; ${ }^{*}$ Chi-square test. 
Table 5. Associations between symptoms of Behçet's disease and mitochondrial deoxyribonucleic acid alterations

\begin{tabular}{lcc}
\hline Symptom & Mitochondrial DNA SNPs & $p$ \\
\hline Deep oral ulcer & $\mathrm{m} .16183 \mathrm{~A}>\mathrm{C}$ & 0.001 \\
& $\mathrm{~m} .16189 \mathrm{~T}>\mathrm{C}$ & 0.042 \\
Posterior oral ulcer & $\mathrm{m} .4883 \mathrm{C}>\mathrm{T}$ & 0.025 \\
& $\mathrm{~m} .5178 \mathrm{C}>\mathrm{A}$ & 0.025 \\
Arthralgia/arthritis & $\mathrm{m} .16182 \mathrm{~A}>\mathrm{C}$ & 0.043 \\
Thrombosis & $\mathrm{m} .16189 \mathrm{~T}>\mathrm{C}$ & 0.048 \\
\hline DNA: Deoxyribonucleic acid; SNP: Single nucleotide polymorphism.
\end{tabular}

$25 \mu \mathrm{L}$ volumes with $1 \mathrm{ng}$ of genomic DNA, $2.5 \mu \mathrm{L}$ of Gold ST*R 10X Buffer (Promega, Madison, Fitchburg, WI, USA), $0.3 \mu \mathrm{L}$ AmpliTaq Gold ${ }^{\circledR}$ DNA Polymerase (5 U/ $\mu \mathrm{L}$, Applied Biosystems, Foster City, CA, USA) and 15 pmol of each primer, using a SimpliAmp ${ }^{\mathrm{TM}}$ Thermal Cycler (Life Technologies, Carlsbad, CA, USA). Cycling parameters were as follows: initial denaturation at $95^{\circ} \mathrm{C}$ for 11 minutes, followed by 35 cycles of $95^{\circ} \mathrm{C}$ for 30 seconds, $60^{\circ} \mathrm{C}$ for 30 seconds, $72^{\circ} \mathrm{C}$ for 60 seconds, and a final extension of $72^{\circ} \mathrm{C}$ for seven minutes. Amplified PCR products were purified using Exo-AP PCR Clean-up (MG MED, Inc., Seoul, Korea). Sanger sequencing was performed using a BigDye Terminator v3.1 Cycle Sequencing Kit (Applied Biosystems, Foster City, CA, USA) with an ABI PRISM 3730 automatic sequencer (Applied Biosystems, Foster City, CA, USA).

\section{Statistical analysis}

Sequencing results were compared with the revised Cambridge Reference Sequence, and the extent of variation that occurred was determined. Chi square or Fisher's exact tests were used to analyze associations of the mitochondrial DNA SNPs with BD susceptibility and its clinical characteristics. We calculated an odds ratio (OR), a 95\% confidence interval (CI), and a two-tailed $\mathrm{p}$-value. All statistical analyses were performed using $\mathrm{R}$ version 3.3.1 (R Foundation for Statistical Computing, Vienna, Austria), based on a significance level of 0.05 .

\section{RESULTS}

Clinical and laboratory characteristics of BD patients were presented in Table 3. Of the patients,
$68.4 \%$ were females and $31.6 \%$ were males, yielding a female to male ratio of 2.16 . The mean ages of the female and the male patients were $48.2 \pm 12.0$ and $47.7 \pm 12.5$ years, respectively. Symptom duration and disease duration after diagnosis did not differ between the female and male patients. Among the clinical and laboratory characteristics of $\mathrm{BD}$ patients, thrombosis was more frequent in male patients than female patients (7 [22.6\%] vs. 0 [0\%], $\mathrm{p}<0.001)$.

Analysis results of the 20 mitochondrial DNA SNPs were shown in Table 4. The frequencies of m.248A $>\mathrm{G}, \mathrm{m} .304 \mathrm{C}>\mathrm{A}, \mathrm{m} .709 \mathrm{G}>\mathrm{A}$, m.3010G $>$ A, m.3970C $>$ T, m.4883C $>$ T, m.5178C $>$ A, m.6392T $>$ C, m.6962G $>$ A, m.10310G $>$ A, m.10609T $>$ C, m.12406G $>$ A, m.12882C $>\mathrm{T}, \quad \mathrm{m} .13928 \mathrm{G}>\mathrm{C}, \quad \mathrm{m} .14668 \mathrm{C}>\mathrm{T}$, $\mathrm{m} .16129 \mathrm{G}>\mathrm{A}$, and $\mathrm{m} 16304 \mathrm{~T}>\mathrm{C}$ did not differ between the $\mathrm{BD}$ and $\mathrm{HC}$ groups. However, $\mathrm{m} .16182 \mathrm{~A}>\mathrm{C}$ and $\mathrm{m} .16183 \mathrm{~A}>\mathrm{C}$ were more common in the patient group than the $\mathrm{HC}$ group (22 [22.4\%] vs. 24 [12.2\%], $\mathrm{p}=0.061$ and 32 [32.7\%] vs. 42 [21.4\%], $p=0.092$ ) although without statistical significance. The m.304C $>$ A SNP was not observed in either the $\mathrm{BD}$ and $\mathrm{HC}$ group.

Thirty-four of the 98 BD patients (34.69\%) had had at least one or more uveitis in their lifetimes (Table 3). The frequencies of female and male patients with histories of uveitis were 22/67 (33\%) and $12 / 31$ (39\%), respectively, and there was no significant difference in mitochondrial DNA SNPs between the two groups $(p=0.734)$.

m.16182A $>$ C, m.16183A $>C, \quad m .16189 \mathrm{~T}>\mathrm{C}$ were not found to be associated with uveitis $(p=0.278,0.239$ and 0.976 , respectively). m.16182A $>C$ was more frequently observed in the patient group than the $\mathrm{HC}$ group, and was significantly associated with methotrexate use, and arthralgia/arthritis ( $p=0.020,0.043$, respectively). $\mathrm{m} .4883 \mathrm{C}>\mathrm{T}$ and $\mathrm{m} .5178 \mathrm{C}>\mathrm{A}$ were associated with posterior location of oral ulcers $(p=0.025$ for each) and $\mathrm{m} .16183 \mathrm{~A}>\mathrm{C}$ was associated with deep oral ulcers $(p=0.001)$, while $m .16189 T>C$ was associated with deep oral ulcers and thrombosis $(p=0.042,0.048$, respectively (Table 5).

\section{DISCUSSION}

In a previous analysis, $\mathrm{m} .248 \mathrm{~A}>\mathrm{G}, \mathrm{m} .709 \mathrm{G}>\mathrm{A}$, m.3970C $>$ T, m.6392T $>C$, m.6962G $>A$, 
m.10310G $>A, \quad m .10609 \mathrm{~T}>\mathrm{C}, \quad \mathrm{m} .12406 \mathrm{G}>\mathrm{A}$, m.12882C $>$ T, m.13928G $>$ C, m.16129G $>A$, and m16304T $>C$ were more frequently observed in the patient group than in $\mathrm{HCs}$, though the effects were without statistical significance. In addition, $\mathrm{m} .16182 \mathrm{~A}>\mathrm{C}$, m.16183A $>\mathrm{C}$, and m.16189T $>\mathrm{C}$ were associated with uveitis $(p=0.041,0.022$, and 0.014 , respectively). The current extended study did not confirm any mitochondrial DNA alterations that had been postulated to be candidate susceptibility mitochondrial SNPs for development of $\mathrm{BD}$ in the previous study. Even though m.16182A $>\mathrm{C}$ and $\mathrm{m} \cdot 16183 \mathrm{~A}>\mathrm{C}$ were more frequent in the patient group (without statistical significance), this was not consistent with the earlier observations. The difference between the two sets of findings might be explained by the fact that different subjects were involved, and certainly the current analysis involving many more subjects ought to be more reliable from a statistical perspective. Secondly, the diagnoses of $\mathrm{BD}$ in the patients examined were based on combinations of symptoms and signs without pathognomonic measures, which could have affected the sensitivity and specificity of the diagnoses.

$\mathrm{m} .16182 \mathrm{~A}>\mathrm{C}$ and $\mathrm{m} .16183 \mathrm{~A}>\mathrm{C}$ were more frequently observed in the patient group than the HC group (22 [22.4\%] vs. 24 [12.2\%], $\mathrm{p}=0.061$ and 32 [32.7\%] vs. 42 [21.4\%], $p=0.092$ ) although the effects did not have statistical significance. They could be defined as SNPs according to the criterion that a SNP should occur in more than $1 \%$ of the population. In the results of Lee et al. ${ }^{6}$ for the whole mitochondrial DNA control region sequences of 593 Korean subjects, m.16182A $>\mathrm{C}$ and $\mathrm{m} .16183 \mathrm{~A}>\mathrm{C}$ were observed in $71(12.0 \%)$ and 143 (24.1\%) subjects respectively. Additionally, in an online human mitochondrial genome database, m.16182A $>C$ and $\mathrm{m} .16183 \mathrm{~A}>\mathrm{C}$ were found in 7,817 (7.0\%) and $16,470(14.7 \%)$ cases, respectively, in 112,173 datasets $(42,616$ full-length and 69,557 control region datasets). ${ }^{7}$ Also, these SNPs were not among the ethnically unique alterations which Han et al. $^{8}$ described among 100 Korean subjects. $\mathrm{m} .16182$ and $\mathrm{m} .16183$ are located in hypervariable region I (HV1, 16024-16383) of the control region of mitochondrial DNA. The control region is an approximately 1000-bp non-coding region that encompasses the displacement loop (D-loop) and promoter regions, which play important roles in mitochondrial ribonucleic acid and DNA synthesis. The D-loop includes three hypervariable segments, HV-I(16024-16383), HV2(57-372), and HV3(438-574) in which mutations are more frequent than in any other mitochondrial DNA regions and result in altered mitochondrial gene replication and/or transcription and mitochondrial gene function, and are responsible for a number of diseases..$^{9-12}$ Links between mitochondria and inflammasomes have been studied to a point where the underlying mechanisms are quite well understood. ${ }^{13-18}$ When there were defects in mitochondrial respiratory enzymes which are encoded by several nuclear and mitochondrial genes, it leaded to excessive reactive oxygen species formation, which in turn activated inflammasomes, and resulted in secretion of proinflammatory cytokines such as interleukin (IL)-1 $\beta$. As some researchers have suggested, $\mathrm{BD}$ might belong to the category of autoinflammatory diseases. ${ }^{1}$ And in line with this viewpoint, we hypothesize that certain mitochondrial genetic alterations in the control region could possibly cause defects in mitochondrial oxidative phosphorylation enzymes (complex I, III, IV and V), increase reactive oxygen species formation, activate inflammasomes, and finally provoke the episodic clinical symptoms and signs of $\mathrm{BD}$.

Several of the mitochondrial SNPs were associated with clinical symptoms and signs; arthralgia with $\mathrm{m} .16182 \mathrm{~A}>\mathrm{C}(\mathrm{p}=0.043)$, posterior location of oral ulcers with $\mathrm{m} .4883 \mathrm{C}>\mathrm{T}$ and m.5178C $>A$ ( $p=0.025$ for each), deep oral ulcers with $\mathrm{m} .16183 \mathrm{~A}>\mathrm{C}(\mathrm{p}=0.001)$ and $\mathrm{m} .16189 \mathrm{~T}>\mathrm{C}$ $(p=0.042)$, and thrombosis with m.16189T $>C$ $(p=0.048)$. These novel findings require further study. Arslan Taş et al. ${ }^{19}$ have reported that neurologic involvement was more frequent in Turkish BD patients with c.769-3C $>\mathrm{T}$ in the mevalonate kinase gene $(p=0.012)$ and, in another Turkish report, CD40 rs1883832 CC and $\mathrm{rs} 1883832 \mathrm{C}$ were found to be associated with genital ulcers (OR 2.30, 95\% CI [1.07-4.94], $\mathrm{p}<0.05$, and, OR 1.78, 95\% CI [1.06-2.97], $\mathrm{p}<0.05$, respectively), although the significance was lost after Bonferroni correction..$^{20}$ The AA and GA genotypes of factor $V$ Leiden polymorphism were seen in Spanish BD patients and in patients with thrombosis (OR 2.51, 95\% CI [1.68-3.74], $\mathrm{p}<0.00001) .{ }^{21}$ In the Han Chinese population, 
IL-10 rs1800871T was associated with BD and genital ulcers, skin lesions, and positive pathergy tests, and haplotypes of IL-17A were associated with a risk of intestinal BD in a Korean report, which suggests that the IL-17/23 axis has a significant role in the pathogenesis of intestinal BD. ${ }^{22,23}$

The more severe clinical manifestations and poorer prognoses of $\mathrm{BD}$ in male patients are well known. Differences between clinical manifestations according to sex were studied among the $98 \mathrm{BD}$ patients in the current study; however, there were no significant differences except that thrombosis was more frequent among the male patients (7 [22.6\%] vs. 0 [0\%], $\mathrm{p}<0.001)$. All seven of the BD patients with thrombosis were male, and the mean age of these patients at enrollment was 44.57 years. One 51-year-old male patient without a history of hypertension, diabetes mellitus or smoking had cerebral infarction, and the other six patients had deep vein thrombosis in the lower legs. A smoking history was present only in one 46-year-old male patient with deep vein thrombosis, indicating that there was no association of thrombosis with smoking in these patients. A Japanese and a further Turkish group have similarly reported that genital ulcers were more frequent among female patients (OR 0.29 , 95\% CI [0.25-0.32], $p<0.001$ and male 971/1138 [85.6\%] vs. female 995/1095 [91.0\%], $\mathrm{p}<0.001),{ }^{24,25}$ while this was not observed in our data. Ocular manifestations showed male predominance in both data sets; on the other hand, only the Turkish group reported male predominance of papulopustular eruptions, thrombophlebitis, and neurologic, pulmonary and vascular involvement.

There are some limitations to the current study. First, there were difficulties enrolling patients because $\mathrm{BD}$ is rare, even though East Asia including Korea is a region with a relatively high prevalence of $\mathrm{BD}$. We had to reduce patient enrollment to half of what was originally intended and even had to extend the enrollment period. Second, an important pitfall of studies recruiting patients and $\mathrm{HCs}$ is the possibility that $\mathrm{HCs}$ could be future patients, and this is a clear limitation of most genetic association studies. Third, aberrant mitochondrial function is very difficult to validate, though there is still value in descriptive mitochondrial genetic studies.
In conclusion, our findings indicate that $\mathrm{m} .16182 \mathrm{~A}>\mathrm{C}$ and $\mathrm{m} .16183 \mathrm{~A}>\mathrm{C}$ may be associated with $\mathrm{BD}$ susceptibility in the Korean population and also suggest some associations of mitochondrial SNPs with clinical characteristics.

\section{Declaration of conflicting interests}

The authors declared no conflicts of interest with respect to the authorship and/or publication of this article.

\section{Funding}

This research was supported by the New Research Program through the National Research Foundation of Korea (NRF) funded by the Ministry of Science, ICT \& Future Planning (grant number, NRF-2017R1C1B2008199) and the Konyang University Myunggok Research Fund of 2015 (grant number; 2015-05).

Some biospecimens for this study were provided by the Chungbuk National University Hospital, a member of the National Biobank of Korea, which is supported by the Ministry of Health, Welfare and Family Affairs. All samples derived from the National Biobank of Korea were obtained with informed consent under institutional review board-approved protocols.

\section{REFERENCES}

1. Haner D, Güher SD. Disease mechanisms. In: Yusuf Y, Hasan Y, editors. Behçet's Syndrome. 1st ed. New York: Springer; 2010. p. 243-64.

2. Xavier JM, Shafiee NM, Ghaderi F, Rosa A, Abdollahi BS, Nadji A, et al. Association of mitochondrial polymorphism m.709G $>$ A with Behçet's disease. Ann Rheum Dis 2011;70:1514-6.

3. Mi-Hye K, Chung-Il J. Genetic Associations of Mitochondrial DNA Polymorphisms with Behçet's Disease in a Korean Population: A Pilot Study. J Rheum Dis 2016;23:23-9.

4. Criteria for diagnosis of Behçet's disease. International Study Group for Behçet's Disease. Lancet 1990;335:1078-80.

5. Miyamoto-Mikami E, Murakami $\mathrm{H}$, Tsuchie $\mathrm{H}$, Takahashi H, Ohiwa N, Miyachi M, et al. Lack of association between genotype score and sprint/power performance in the Japanese population. J Sci Med Sport 2017;20:98-103.

6. Lee HY, Yoo JE, Park MJ, Chung U, Shin KJ. Mitochondrial DNA control region sequences in Koreans: identification of useful variable sites and phylogenetic analysis for mtDNA data quality control. Int J Legal Med 2006;120:5-14. 
7. MITOMAP A human mitochondrial genome database. Available from: https://www.mitomap.org/foswiki/ bin/view/MITOMAP/WebHome. Updated 2018. [Acessed: May 15, 2018].

8. Han JS, Lee DH, Rho HM. Short Communication: Characteristics of hypervariable regions of mitochondrial DNA in Korean Population. BMB Reports 1998;31:604-6.

9. Stoneking M. Hypervariable sites in the mtDNA control region are mutational hotspots. Am J Hum Genet 2000;67:1029-32.

10. Andres MP, Cardena MMSG, Fridman C, Podgaec S. Polymorphisms of mitochondrial DNA control region are associated to endometriosis. J Assist Reprod Genet 2018;35:533-8.

11. Kao SH, Huang HC, Hsieh RH, Chen SC, Tsai MC, Tzeng CR. Oxidative damage and mitochondrial DNA mutations with endometriosis. Ann N Y Acad Sci 2005;1042:186-94.

12. Polyak K, Li Y, Zhu H, Lengauer C, Willson JK, Markowitz SD, et al. Somatic mutations of the mitochondrial genome in human colorectal tumours. Nat Genet 1998;20:291-3.

13. Heid ME, Keyel PA, Kamga C, Shiva S, Watkins $\mathrm{SC}$, Salter RD. Mitochondrial reactive oxygen species induces NLRP3-dependent lysosomal damage and inflammasome activation. J Immunol 2013;191:5230-8.

14. de Lavera I, Pavon AD, Paz MV, Oropesa-Avila M, de la Mata M, Alcocer-Gomez E, Garrido-Maraver $\mathrm{J}$, et al. The Connections Among Autophagy, Inflammasome and Mitochondria. Curr Drug Targets 2017;18:1030-8.

15. Iyer SS, He Q, Janczy JR, Elliott EI, Zhong Z, Olivier AK, et al. Mitochondrial cardiolipin is required for Nlrp3 inflammasome activation. Immunity 2013;39:311-23.

16. Jabaut J, Ather JL, Taracanova A, Poynter ME, Ckless K. Mitochondria-targeted drugs enhance Nlrp3 inflammasome-dependent IL-1 $\beta$ secretion in association with alterations in cellular redox and energy status. Free Radic Biol Med 2013;60:233-45.
17. Kepp O, Galluzzi L, Kroemer G. Mitochondrial control of the NLRP3 inflammasome. Nat Immunol 2011;12:199-200.

18. López-Armada MJ, Riveiro-Naveira RR, VaamondeGarcía C, Valcárcel-Ares MN. Mitochondrial dysfunction and the inflammatory response. Mitochondrion 2013;13:106-18.

19. Arslan Taş D, Erken E, Yildiz F, Dinkçi S, Sakalli H. Mevalonate kinase gene mutations and their clinical correlations in Behçet's disease. Int $J$ Rheum Dis 2014;17:435-43.

20. İnal EE, Rüstemoğlu A, İnanır A, Ekinci D, Gül Ü, Yiğit $\mathrm{S}$, et al. Associations of rs4810485 and rs1883832 polymorphisms of CD40 gene with susceptibility and clinical findings of Behçet's disease. Rheumatol Int 2015;35:837-43.

21. Chamorro AJ, Marcos M, Hernández-García I, Calvo A, Mejia JC, Cervera R, et al. Association of allelic variants of factor $\mathrm{V}$ Leiden, prothrombin and methylenetetrahydrofolate reductase with thrombosis or ocular involvement in Behçet's disease: a systematic review and meta-analysis. Autoimmun Rev 2013;12:607-16.

22. Hu J, Hou S, Zhu X, Fang J, Zhou Y, Liu Y, et al. Interleukin-10 gene polymorphisms are associated with Behcet's disease but not with Vogt-KoyanagiHarada syndrome in the Chinese Han population. Mol Vis 2015;21:589-603.

23. Kim ES, Kim SW, Moon CM, Park JJ, Kim TI, Kim $\mathrm{WH}$, et al. Interactions between IL17A, IL23R, and STAT4 polymorphisms confer susceptibility to intestinal Behcet's disease in Korean population. Life Sci 2012;90:740-6.

24. Ishido T, Horita N, Takeuchi M, Kawagoe T, Shibuya $\mathrm{E}$, Yamane T, et al. Clinical manifestations of Behçet's disease depending on sex and age: results from Japanese nationwide registration. Rheumatology (Oxford) 2017;56:1918-27.

25. Tursen U, Gurler A, Boyvat A. Evaluation of clinical findings according to sex in 2313 Turkish patients with Behçet's disease. Int $J$ Dermatol 2003;42:346-51. 